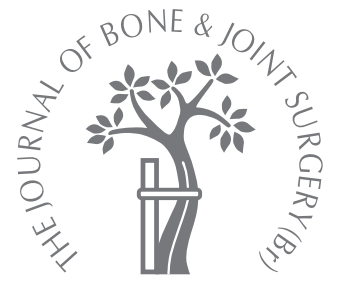

\title{
Varus-valgus balance and range of movement after total knee arthroplasty
}

\author{
Y. Matsuda, \\ Y. Ishii, \\ H. Noguchi, \\ R. Ishii \\ From the Ishii \\ Orthopaedic and \\ Rehabilitation Clinic, \\ Gyoda, Saitama, \\ Japan
}

We performed a randomised, prospective study of 80 mobile-bearing total knee arthroplasties (80 knees) in order to measure the effects of varus-valgus laxity and balance on the range of movement (ROM) one year after operation. Forty knees had a posteriorcruciate-ligament (PCL)-retaining prosthesis and the other 40 a PCL-sacrificing prosthesis. In the balanced group (69 knees) in which the difference between varus and valgus was less than $2^{\circ}$, the mean ROM improved significantly from $107.6^{\circ}$ to $117.7^{\circ}(\mathrm{p}<0.0001)$. By contrast, in the 11 knees which were unbalanced and in which the difference between varus and valgus laxity exceeded $2^{\circ}$, the ROM decreased from a mean of $121.0^{\circ}$ to $112.7^{\circ}(p=0.0061$ ). We conclude that coronal laxity, especially balanced laxity, is important for achieving an improved ROM in mobile-bearing total knee arthroplasty.

A satisfactory post-operative range of movement $(\mathrm{ROM})$ is an important feature of a successful total knee arthroplasty (TKA) and is influenced by many factors. A successful outcome is also assumed to include satisfactory stability. While there is general agreement about the importance of varus-valgus laxity and proper soft-tissue balance at TKA, there is little appropriate information in the literature. Thus we investigated the effect of coronal laxity, varus-valgus balance and the type of implant on ROM after TKA.

\section{Patients and Methods}

We examined 80 low-contact stress TKAs (LCS; DePuy, Warsaw, Indiana) chosen from a group of patients who had no clinical complications. Forty knees (40 patients) were prospectively assigned to receive a posteriorcruciate-ligament (PCL)-retaining prosthesis. The mean age of the patients was 70 years, their mean ROM before operation was $118^{\circ}$ (SD $14^{\circ}$ ), and their mean pre-operative Hospital for Special Surgery (HSS) $\operatorname{score}^{1}$ was $92^{\circ}$ $\left(\mathrm{SD} 2^{\circ}\right.$ ). Forty knees (40 patients) were prospectively assigned to receive a PCL-sacrificing prosthesis. Their mean age was 72 years, their mean ROM $116^{\circ}$ (SD $14^{\circ}$ ), and the mean preoperative HSS score $90^{\circ}\left(\mathrm{SD} 4^{\circ}\right)$. Table I shows the clinical details of each group. All procedures were performed by one senior surgeon (YI) using a standard technique, including the necessary soft-tissue release required to obtain adequate balance. Proper intra-operative laxity was judged manually rather than measured. All the components were secured without cement. No cases of revision replacement or conversion from a high tibial osteotomy were included in the study.

Varus-valgus laxity was measured using a Telos arthrometer (Fa Telos; MedizinischTechnische GmbH, Griesheim, Germany).

Orthopaedic Physiotherapist Ishii Orthopaedic and Rehabilitation Clinic, 1089

Shimo-Oshi, Gyoda, Saitama 361-0037, Japan.

Correspondence should be sent to DrY. Matsuda; e-mail: ymatsuda802@nifty.com

C2005 British Editorial Society of Bone and Joint Surgery doi:10.1302/0301-620X.87B6. $15256 \$ 2.00$

$J$ Bone Joint Surg $[\mathrm{Br}]$ 2005;87-B:804-8.

Received 30 December 2003 ; Accepted after revision 14 December 2004

Table I. Details of the patients in both groups

\begin{tabular}{|c|c|c|}
\hline & PCLR $^{\dagger}$ & PCLS $^{\ddagger}$ \\
\hline Patients (knees) & $40(40)$ & $40(40)$ \\
\hline Male & 6 & 2 \\
\hline Female & 34 & 38 \\
\hline Mean flexion $\left({ }^{\circ}\right)(\mathrm{SD})$ & $118(14)$ & $116(14)$ \\
\hline $\mathrm{HSS}^{*}$ score (SD) & $92(2)$ & $90(4)$ \\
\hline Mean posterior tibial slope $\left({ }^{\circ}\right)(\mathrm{SD})$ & $10.5(2.5)$ & $9.6(2.5)$ \\
\hline Mean pre-operative posterior condylar offset ${ }^{25}(\mathrm{~mm})$ (SD) & $24.9(1.9)$ & $25.3(1.4)$ \\
\hline Mean post-operative posterior condylar offset ${ }^{25}(\mathrm{~mm})$ (SD) & $23.2(2.0)$ & $23.4(2.5)$ \\
\hline
\end{tabular}




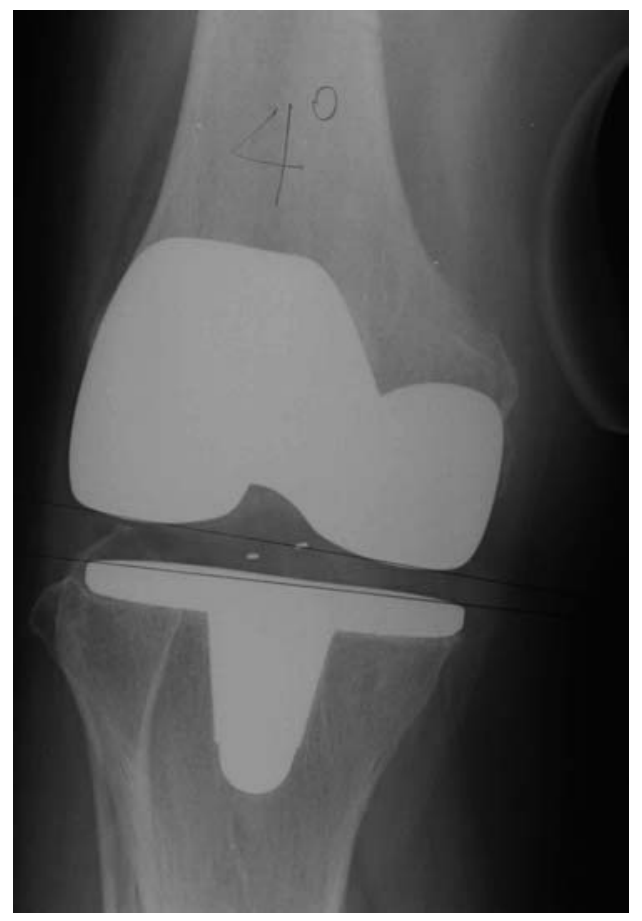

Fig. 1a

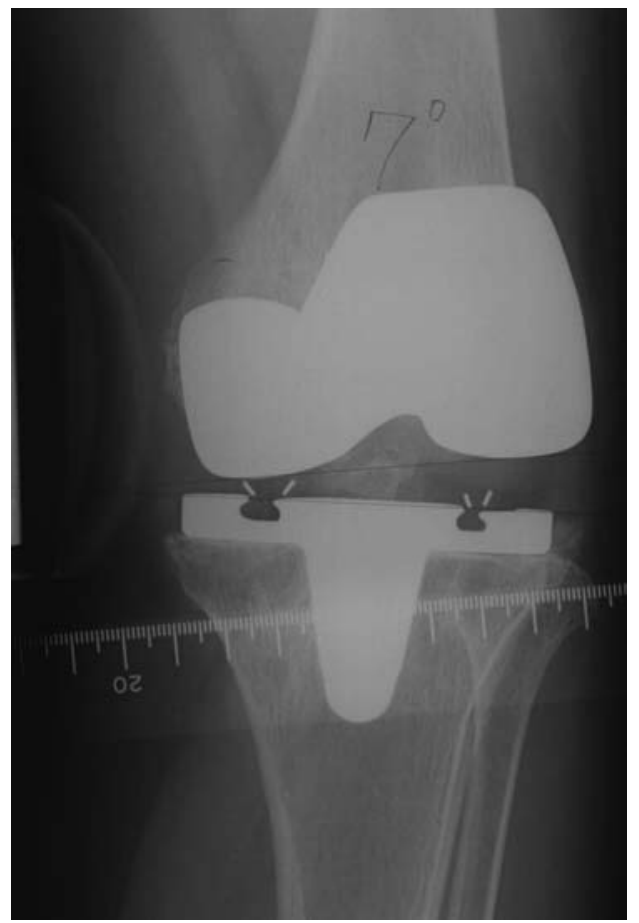

Fig. 1c

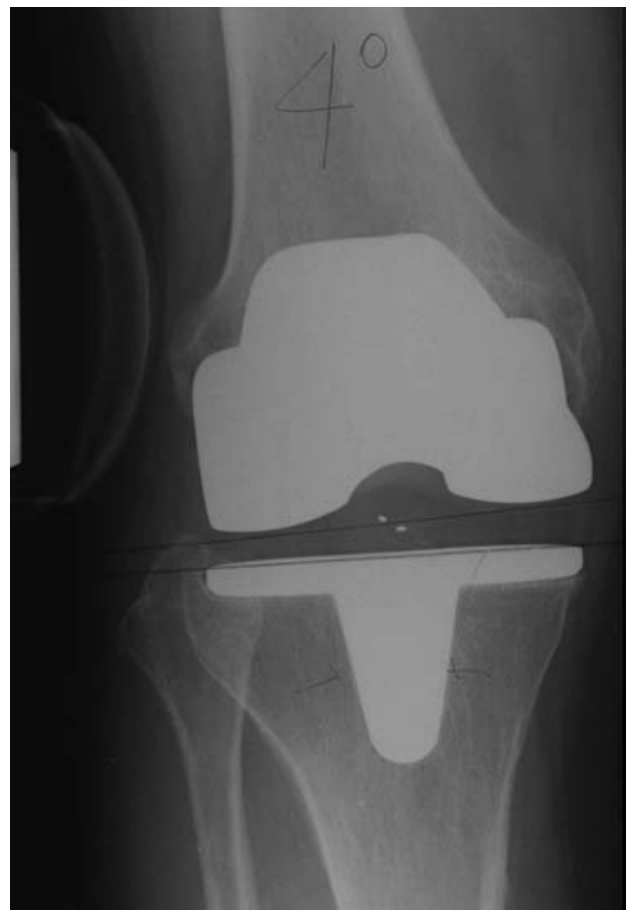

Fig. 1b

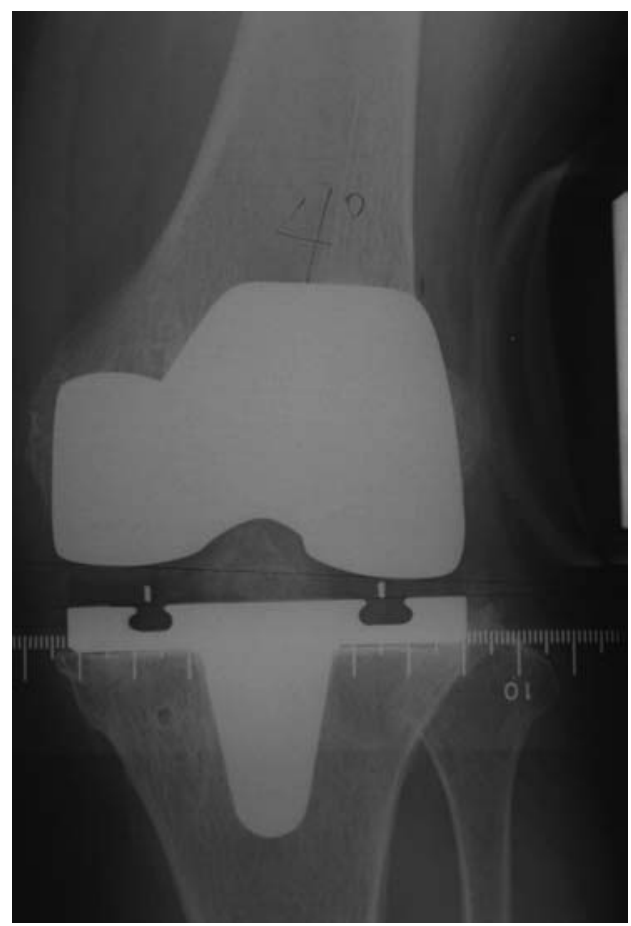

Fig. 1d

Radiographs showing a) varus, and b) valgus stress in a PCL-sacrificing TKA with balanced coronal laxity; and c) varus and d) valgus stress in a PCL-retaining TKA with unbalanced coronal laxity.

With the patient lying supine, $150 \mathrm{~N}$ were applied across the knee with the joint flexed at between $0^{\circ}$ and $20^{\circ}$ (Fig. 1) and the patella facing forward in order to minimise the rotational effect. The patients were told to relax and stan- dard radiographs were taken after the force had been applied for one minute. In order to reduce interobserver variation, a single clinician (YM) performed all of the tests. Three measurements were made one year after operation 
Table II. Mean (SD) laxity at varus and valgus angles in both groups one year after TKA

\begin{tabular}{llll}
\hline & Varus & Valgus & Total laxity \\
\hline PCLR $^{*}(n=40)$ & $3.9(1.2)$ & $4.0(1.4)$ & $7.9(2.3)$ \\
$\operatorname{PCLS}^{\dagger}(n=40)$ & $4.7(2.2)$ & $3.6(1.4)$ & $8.3(2.9)$ \\
p value & 0.1534 & 0.2222 & 0.9851 \\
\hline
\end{tabular}

* PCLR, posterior cruciate ligament-retaining design prosthesis

† PCLS, posterior cruciate ligament-sacrificing design prosthesis

and their mean was calculated. The intrasubject error was less than $1^{\circ}$. Statistically, a paired $t$-test was used to compare the results for varus and valgus laxity within each group, and an unpaired $t$-test for the two groups. Values for $\mathrm{p}<0.05$ were regarded as being significant.

The ROM for all patients was measured before and one year after surgery. It has been reported that the ROM after TKA does not change significantly after one year. ${ }^{2,3}$ Considering our results (Table II), and those in previous reports, ${ }^{4,5}$ approximately $4^{\circ}$ of unidirectional laxity and $8^{\circ}$ of total coronal laxity were considered to be the optimal degrees of laxity for both the posterior cruciate ligament retaining and sacrificing designs. Both forms of the prosthesis have iden- tical radii of curvature from $0^{\circ}$ to $30^{\circ}$ of flexion in the anteroposterior and mediolateral planes, although the contact area in the two designs differs slightly.

All the patients were divided into balanced and unbalanced groups according to whether the difference in varusvalgus laxity was $<2^{\circ}$. An unpaired $t$-test was used to compare the two groups.

Three separate subgroups in terms of total laxity were analysed and compared. They were defined as tight $\left(<6^{\circ}\right)$, adequate $\left(\geq 6^{\circ}\right.$ but $\left.\leq 10^{\circ}\right)$, and loose $\left(>10^{\circ}\right)$.

\section{Results}

Table II gives the mean measurements under varus and valgus strains in both groups one year after TKA. There was no significant difference between the two groups ( $\mathrm{p}>0.05)$. The ROM data for both groups are summarised in Table III. There was a statistically significant improvement in the ROM 12 months after surgery for both groups.

The relationship between total coronal laxity and the ROM is summarised in Table IV. All three laxity groups showed an improved range compared with the pre-operative measurements. The improvement between the pre- and

Table III. Mean (SD) range of movement $\left({ }^{\circ}\right.$ ) one year after TKA with the percentage improvement

\begin{tabular}{lllll}
\hline & Pre-operative ( ${ }^{\circ} ;$ SD) & Post-operative ( ${ }^{\circ} ;$ SD) & Improvement (\%; SD) & p value \\
\hline $\operatorname{PCLR}^{*}(n=40)$ & $109.1(18.0)$ & $117.6(14.4)$ & $7.8(21.5)$ & 0.0087 \\
$\operatorname{PCLS}^{\dagger}(\mathrm{n}=40)$ & $109.9(18.8)$ & $116.3(14.0)$ & $5.8(15.8)$ & 0.0123 \\
$\mathrm{p}$ value & 0.8571 & 0.6933 & 0.5528 & \\
\hline
\end{tabular}

* PCLR, posterior cruciate ligament-retaining design prosthesis

† PCLS, posterior cruciate ligament-sacrificing design prosthesis

Table IV. Mean (SD) flexion and range of movement $\left({ }^{\circ}\right)$ in the tight, adequate, and loose groups with the percentage improvement

\begin{tabular}{lllll}
\hline & Pre-operative $\left(^{\circ} ;\right.$ SD) & Post-operative $\left(^{\circ} ;\right.$ SD) & Improvement (\%; SD) & p value \\
\hline Tight $(n=9)$ & $107.5(20.0)$ & $109.4(13.2)$ & $1.8(21.7)$ & 0.4704 \\
Adequate $(n=60)$ & $107.4(18.3)$ & $115.8(13.9)$ & $7.8(19.6)$ & 0.0005 \\
Loose $(n=11)$ & $122.3(12.3)$ & $126.8(13.1)$ & $3.7(14.6)$ & 0.4275 \\
\hline
\end{tabular}

Table V. Mean (SD) range of movement $\left({ }^{\circ}\right.$ ) in the balanced and unbalanced groups with the percentage improvement

\begin{tabular}{lllll}
\hline & Pre-operative $\left(^{\circ} ;\right.$ SD) & Post-operative $\left(^{\circ} ;\right.$ SD) & Improvement (\%; SD) & p value \\
\hline Balanced $(n=69)$ & $107.6(17.6)$ & $117.7(13.6)$ & $9.4(18.5)$ & $<0.0001$ \\
Unbalanced $(n=11)$ & $121.0(18.6)$ & $112.7(17.5)$ & $-6.8(17.4)$ & 0.2131 \\
p value & 0.0515 & 0.2839 & 0.0061 & \\
\hline
\end{tabular}

Table VI. Mean (SD) laxity and range of movement $\left({ }^{\circ}\right)$ in both the balanced and unbalanced groups with the percentage improvement

\begin{tabular}{lllll}
\hline & Pre-operative $\left(^{\circ} ;\right.$ SD) & Post-operative $\left(^{\circ} ;\right.$ SD) & Improvement (\%; SD) & p value \\
\hline Balanced & & & & \\
$\quad$ Tight $(n=9)$ & $107.5(20.0)$ & $109.4(13.2)$ & $1.8(21.7)$ & 0.4704 \\
$\quad$ Adequate $(n=54)$ & $106.9(18.2)$ & $117.3(13.3)$ & $9.7(18.8)$ & $<0.0001$ \\
$\quad$ Loose $(n=6)$ & $114.2(8.6)$ & $128.3(12.1)$ & $12.3(9.9)$ & 0.0228 \\
Unbalanced & & & & \\
$\quad$ Tight $(n=0)$ & $111.7(20.2)$ & $102.5(12.1)$ & $-8.2(21.0)$ & 0.3718 \\
$\quad$ Adequate $(n=6)$ & $132.0(8.4)$ & $125.0(15.4)$ & $-5.3(14.4)$ & 0.4684 \\
$\quad$ Loose $(n=5)$ & & & & \\
\hline
\end{tabular}


post-operative ROM was only statistically significant for the adequate group.

Table $\mathrm{V}$ shows the mean ROM before and at one year after surgery for the balanced and unbalanced groups. The ROM only improved significantly for the balanced group. For the unbalanced group it decreased. There was no significant difference between the pre-operative ROM and that immediately after surgery between the two groups.

The details of both balanced and unbalanced groups are summarised in Table VI. By one year after surgery all three subgroups for the balanced knees had a better ROM when compared with their pre-operative ROM. Both the adequate and loose knees achieved a significantly better ROM. In contrast, for the unbalanced group, both the adequate and loose knees lost movement.

\section{Discussion}

Adequate soft-tissue balance has a greater effect on the outcome of a mobile-bearing TKA than on that of a fixed-bearing one. ${ }^{6,7}$ However, the post-operative ROM is important for maintaining the activities of daily living, such as squatting or sitting. ${ }^{7}$ According to Kettelkamp et $\mathrm{al}^{8}$ and Laubenthal, Smidt and Kettelkamp ${ }^{9}$ the normal ROM of the knees is $0^{\circ}$ to $140^{\circ} ; 67^{\circ}$ of flexion is required in the swing phase of walking, $80^{\circ}$ for climbing stairs, $90^{\circ}$ for descending stairs and $93^{\circ}$ for sitting on a chair. Significant factors affecting the outcome include pre-operative flexion, ${ }^{3,10-13}$ the tibiofemoral varus-valgus angle, ${ }^{3,11}$ the age of the patient, ${ }^{3}$ body-weight, ${ }^{12}$ the technique of surgical closure ${ }^{14}$ and the design of the implant. ${ }^{15,16}$ Based upon a review of the literature, most clinical series have studied patients who were considered to be clinically successful and showed no significant instability. We have evaluated the 80 LCS knees as one group and present the results in a simpler manner.

Tables I and III show that both groups had similar clinical results in terms of the HSS score and post-operative ROM. Furthermore, Table II shows that both also had similar varus-valgus laxity, although the posterior cruciate ligament is thought to be the second stabiliser and to contribute $25 \%$ of the varus-valgus stability as compared with the collateral ligaments. ${ }^{17,18}$

As to whether laxity influences the ROM, Edwards, Miller and Chan ${ }^{19}$ reported that patients with stable knees had a mean maximum flexion of $105^{\circ}$ whereas those with lax knees had a mean maximum flexion of $111^{\circ}$, although the difference did not achieve statistical significance. We presume from this that some degree of laxity is an important factor. In our study, the ROM was improved in all the laxity groups, but the improvement was only significant in the adequate group. These results clearly demonstrate that a better ROM is to be expected in those patients with adequate knee laxity and may support published opinions that less laxity, or tightness, places excessive shear forces on the component-bone interface. However, greater laxity places greater force on the restraining soft tissues and results in the risk of too large a shift of the contact points, thereby rock- ing the components. ${ }^{20}$ In our loose laxity group, a better, albeit insignificant, ROM was achieved, although the preoperative ROM was greater than in the tight and adequate laxity groups.

Although there is general agreement about the importance of obtaining soft-tissue balance in TKA, it has not been critically measured. Our study indicated that patients with balanced laxity had a higher probability of achieving a better ROM than those with unbalanced laxity $(\mathrm{p}<0.0001)$. Furthermore, the rate of improvement was significantly greater for the balanced than the unbalanced group, although the latter had had a greater pre-operative ROM. There are two possible reasons for these results. First, the unbalanced group had fewer knees of adequate stability $(54.5 \%)$ and more loose knees $(45.5 \%)$ than the balanced group, which include tight $(13.0 \%)$, adequate $(78.3 \%)$ and loose $(8.7 \%)$ knees. The other reason is that the design of the LCS implant affected these results. Some authors ${ }^{21-23}$ have reported a mean post-operative ROM of between $102^{\circ}$ and $120^{\circ}$ using the LCS prosthesis. This may reflect the fact that unbalanced laxity is undesirable since it may produce eccentric loading of the implant ${ }^{24}$ and soft-tissue impingement.

Table VI shows that the ROM decreased by $8.2 \%$ in patients with unbalanced laxity, even in those with adequate laxity. Our results indicate that balanced laxity is essential for achieving a better ROM after TKA. Furthermore, Table VI also demonstrates that a better ROM is to be expected in balanced knees. However, it is very difficult to achieve balance with loose laxity. In our loose laxity group, five of $11(45.5 \%)$ knees were unbalanced and the ROM decreased from $132.0^{\circ}$ to $125.0^{\circ}$ (5.3\%).

There are some limitations in our study. This was a static analysis of coronal laxity, undertaken on one occasion, 12 months after surgery. We only measured varus-valgus laxity with the knee in extension, because of the characteristics of the arthrometer. Although the contact areas between the two designs differed, our study was performed under static, non-weight-bearing conditions, so that these differences were minimal in this effect.

We conclude that both coronal laxity and varus-valgus balance affect the ROM after TKA. An adequate degree of laxity and balance should contribute positively to the outcome of TKA.

\section{Supplementary material}

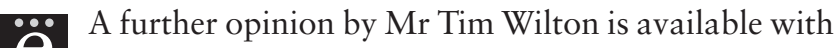 the electronic version of this article on our website at www.jbjs.org.uk

No benefits in any form have been received or will be received from a commercial party related directly or indirectly to the subject of this article.

\section{References}

1. Alicea J. Scoring systems and their validation for the arthritic knee. In: Insall JN, Scott WN, eds. Surgery of the knee. Vol. 2. New York: Churchill Livingstone, 2001: 1507-15.

2. Insall JN, Hood RW, Flawn LB, Sullivan DJ. The total condylar knee prosthesis in gonarthrosis: a five to nine-year follow-up of the first one hundred consecutive replacements. J Bone Joint Surg [Am] 1983;65-A:619-28. 
3. Schurman DJ, Parker JN, Ornstein D. Total condylar knee replacement: a study of factors influencing range of motion as late as two years after arthroplasty. J Bone Joint Surg [Am] 1985;67-A:1006-14.

4. Ishii Y, Matsuda Y, Ishii R, Sakata S, Omori G. Coronal laxity in extension in vivo after total knee arthroplasty. J Orthop Sci 2003;8:538-42.

5. Matsuda Y, Ishiii Y. In vivo laxity of LCS mobile bearing prostheses. Clin Orthop 2004:419:138-43

6. Vertullo CJ, Easley ME, Scott WN, Insall JN. Mobile bearings in primary knee arthroplasty. J Am Acad Orthop Surg 2001;6:355-64.

7. Kim JM, Moon MS. Squatting following total knee arthroplasty. Clin Orthop 1995; 313:177-86.

8. Kettelkamp DB, Johnson RJ, Smidt GL, Chao EY, Walker M. An electrogoniometric study of knee motion in normal gait. J Bone Joint Surg [Am] 1970;52-A:77590.

9. Laubenthal KN, Smidt GL, Kettelkamp DB. A quantitative analysis of knee motion during activities of daily living. Phys Ther 1972;52:34-43.

10. Anouchi YS, McShane M, Kelly F Jr, Elting J, Stiehl J. Range of motion in total knee replacement. Clin Orthop 1996;331:87-92.

11. Harvey IA, Barry K, Kirby SPJ, Johnson R, Elloy MA. Factors affecting the range of movement of total knee arthroplasty. J Bone Joint Surg [Br] 1993;75-B:950-5.

12. Lizaur A, Marco L, Cebrian R. Preoperative factors influencing the range of movement after total knee arthroplasty for severe osteoarthritis. J Bone Joint Surg [Br] 1997;79-B:626-9

13. Parsley BS, Engh GA, Dwyer KA. Preoperative flexion: does it influence postoperative flexion after posterior-cruciate-retaining total knee arthroplasty? Clin Orthop 1992;275:204-10.

14. Emerson RH Jr, Ayers C, Head WC, Higgins LL. Surgical closing in primary total knee arthroplasties: flexion versus extension. Clin Orthop 1996;331:74-80.
15. Dennis DA, Komistek RD, Stiehl JB, Walker SA, Dennis KN. Range of motion after total knee arthroplasty: the effect of implant design and weight-bearing conditions. J Arthroplasty 1998;13:748-52.

16. Maloney WJ, Schurman DJ. The effects of implant design on range of motion after total knee arthroplasty: total condylar versus posterior stabilized total condylar designs. Clin Orthop 1992;278:147-52.

17. Burstein AH, Wright TM. Basic biomechanics. In: Insall JN, Scott WN, eds. Surgery of the knee. Vol. 2. New York: Churchill Livingstone, 2001:215-31.

18. Grood ES, Noyes FR, Butler DL, Suntay WJ. Ligamentous and capsular restraints preventing straight medial and lateral laxity in intact human cadaver knees. J Bone Joint Surg [Am] 1981;63-A:1257-69.

19. Edwards E, Miller J, Chan K-H. The effect of postoperative collateral ligament laxity in total knee arthroplasty. Clin Orthop 1988;236:44-51.

20. Walker PS, Garg A. Range of motion in total knee arthroplasty: a computer analysis. Clin Orthop 1991:262:227-35.

21. Stiehl JB, Voorhorst PE, Keblish PA, Sorrells RB. Comparison of range of motion after posterior cruciate retention or sacrificing with a mobile bearing total knee arthroplasty. Am J Knee Surg 1997;10:216-20.

22. Stiehl JB, Voorhorst PE. Total knee arthroplasty with a mobile-bearing prosthesis: comparison of retention and sacrifice of the posterior cruciate ligament in cementless implants. Am J Orthop 1999;28:223-8.

23. Callaghan JJ, Squire MW, Goetz DD, Sulivan PM, Johnston RC. Cemented rotating-platform total knee replacement: a nine to twelve-year follow-up study. J Bone Joint Surg [Am] 2000;82-A:705-11.

24. Walker PS, Ranawat C, Insall J. Fixation of the tibial components of condylar replacement knee prosthesis. J Biomech 1976;9:269-75.

25. Bellemans J, Banks S, Victor J, Vandenneucker H, Moemans A. Fluoroscopic analysis of the kinematics of deep flexion in total knee arthroplasty: influence of posterior condylar offset. J Bone Joint Surg [Br] 2002;84-B:50-3 